\title{
Role of wall temperature on shock train in a rectangular isolator
}

\author{
Hongbo Lu, Dan Wang and Xing Chen \\ China Academy of Aerospace Aerodynamics, Beijing 100074, China \\ Lianjie Yue ${ }^{1}$ \\ Institute of Mechanics, Chinese Academy of Sciences, Beijing 100190, China
}

\begin{abstract}
Aimed at the problem of isolator being seriously heated by aeroheating at a long time fly, effects of wall temperature on flow characteristics and performance of isolator are experimentally and numerically investigated in detail under the different entrance conditions including total temperature and total pressure. The results show that shock train is affected by the dual mechanism of isolator wall temperature and airflow total temperature. With an increase of wall temperature and a reduction of total temperature, the length of shock train increases. This tendency can be characterized by the variation of shock train length with ratio of wall temperature to total temperature, viz., shock train length increases with ratio of wall temperature to total temperature. Based on the present data, both the ratio of wall temperature to total temperature and specific heat ratio are introduced to modify the correlation of Waltrup and Billig [5] for predicting shock train length of practical design with the coverage of more physical influencing factors.
\end{abstract}

\section{Nomenclature}

$H=$ Duct height, $50 \mathrm{~mm}$

$M a=$ Mach number

$P \quad=\quad$ Pressure

$R e_{\theta}=$ Reynolds number based boundary layer momentum thickness

$R=$ Gas constant

$s \quad=\quad$ shock train length

$T=$ Temperature

$x=$ Streamwise coordinate originating at the isolator entrance

$\mathrm{y}=$ Transverse coordinate originating at the half isolator height

$\theta=$ boundary-layer momentum thickness

$\gamma \quad=\quad$ Specific heat ratio

$\rho \quad=$ Density

\footnotetext{
1 Professor, State Key Laboratory of High Temperature Gas Dynamics, Beisihuan West Road No.15, Haidian District, Beijing, China. yuelj@imech.ac.cn (Corresponding author).
} 


\section{Subscript}

$$
\begin{aligned}
\mathrm{B} 13 & =\text { Last measured point on the isolator bottom wall } \\
\mathrm{b} & =\text { Isolator exit } \\
\mathrm{T} 1 & =\text { First measured point on the isolator top wall } \\
\mathrm{t} & =\text { Stagnation condition } \\
\mathrm{w} & =\text { Wall } \\
1 & =\text { Isolator entrance or starting position of shock train }
\end{aligned}
$$

\section{Introduction}

An isolator module is a constant or nearly constant area duct located between the inlet and combustor of scramjet [1-2]. Its role is to house shock train induced by heat release in a combustor and extend engine operation conditions such as higher equivalence ratio without incurring spillage or unstart [3]. In engine design, the isolator length has to be optimal to minimize the weight and drag of the overall system and fully hold shock train, and therefore it is vital to well understand shock train behavior and accurately calculate shock train length in the isolator under flight conditions. To resolve these issues, numerous investigations [4-13] have performed to examine the influence of parameters such as the entrance conditions, the exit back pressure ratio and geometric effects. It is found that the occurrence of shock train pattern strongly depends on the upstream Mach number and the boundary layer thickness. According to the review of Mtsuo et al. [4], there exist three basic shock structures for confined flows. When the approach Mach number is very low or upstream boundary layer is very thin, a single normal shock may exist. As the boundary layer thickness increases at low Mach numbers, a series of bifurcated normal shocks (normal shock train) form, along with a small boundary layer separation. At higher Mach numbers, a more severe shock wave-boundary layer interaction occurs, leading to the formation of multiple crossing oblique shocks ( $\mathrm{x}$-shaped shock train) with large scale separations. It is also revealed that for a given entrance condition, shock train length increases with an increase of the exit back pressure, and pressure profiles inside shock train present a similarity. Based on the experimental data measured from cylindrical ducts, Waltrup and Billig [5] developed an empirical relationship, which correlates shock train length (s) with Mach number $\left(\mathrm{Ma}_{1}\right)$, back pressure ratio $\left(\mathrm{P}_{\mathrm{b}} / \mathrm{P}_{1}\right)$, boundary-layer momentum thickness $(\theta)$, Reynolds number $\left(\mathrm{Re}_{\theta}\right)$ and 
duct diameter (D). For a given back pressure ratio, shock train length varies inversely with $\left(\mathrm{Ma}_{1}{ }^{2}-1\right) \operatorname{Re}_{\theta}{ }^{1 / 4}$ and directly with $(\mathrm{D} \theta)^{1 / 2}$. For a given upstream flow properties, shock train length is a quadratic function of $\mathrm{P}_{\mathrm{b}} / \mathrm{P}_{1}$. A further study by Bement et al. [11] confirmed that the Waltrup and Billig correlation is also applicable to calculate shock train length in a rectangular isolator by replacing cylinder diameter with duct height of rectangular section, but a discrepancy exist between the predicted curve and experimental data. The difference should be attributed to geometric differences [12-13].

These fruitful achievements promote a deep understanding of shock train structures and isolator design, but most of results are obtained using room-temperature supply air or cold air as flow gas $\left(\mathrm{T}_{\mathrm{t}}=300 \mathrm{~K}\right)$, so that the role of air temperature and heat transferred from airflow to the isolator wall cannot be taken into account. At real flight conditions, the air temperature in the isolator is high, and the isolator walls are also subjected to severe aerodynamic heating $[14,15]$, resulting in the isolator surfaces being heated up. Accordingly, the boundary layer thickness on the wetted surfaces increases, as well as an increase of the gas static temperature in the boundary layer, reducing the fullness of boundary layer profile and the gas density. Thus an increase of wall temperature will lead to a more likely separation of boundary layer, as Coet and Chanetz [16], Bleilebens and Olivier [17], Olivier and Habermann [18], Reinartz [19] and John et al. [20] discovered. Their work also suggests that the boundary layer separation scale induced by shock wave increases with an increase of wall temperature. From these results, it can be inferred that the ability of isolator holding shock train will go down with an increase of wall temperature. This tendency coincides with the research results of Cuffel [15], Fisher et al. [21-23] and Lin et al. [24, 25], but is contrary to the findings of Fischer and Olivier [26]. Fischer and Olivier [26] believed that the opposite effect should be attributed to the wall being heated up beyond the recovery temperature of the airflow. Furthermore, the boundary-layer profile in the correlation of Waltrup and Billig [5] is denoted by boundary-layer momentum thickness, which indirectly involves the wall temperature influences, 
but whether it fully covers the wall temperature effects or not still need be checked. As mentioned above, the effects of surface temperature and gas total temperature on shock train have not been well elucidated. This paper describes our recent efforts in confirming the effects of surface temperature on shock train and isolator performance by a combination of experimental and numerical tests.

\section{Experimental and numerical description}

\section{A. Experimental description}

Experiments described here were carried out in a direct-connect test facility, composed of a heater, a 2D nozzle, an isolator and a throttle valve to simulate back pressure rise induced by heat release. In the heater, compressed dry air was heated to the required total temperature $\left(\mathrm{T}_{\mathrm{t}}\right)$ and total pressure $\left(\mathrm{P}_{\mathrm{t}}\right)$ by hydrogen combustion and oxygen replenishment. A two dimensional nozzle designed for a Mach number of 2.5 was used in conjunction with a nearly constant-area isolator with a length of $600 \mathrm{~mm}$ and a cross-section area of $50 \times 70 \mathrm{~mm}^{2}$. Isolator walls were uniformly heated by a heated ceramic chip, and wall temperatures of vertical and horizontal sides were almost identical. Wall static pressure taps were located on the centerline of the top, bottom and side wall, respectively, as shown in Fig. 1. On the top wall, there were 24 pressure transducers at intervals of $20 \mathrm{~mm}$, denoted by "T1 T24" in Fig. 1. On the bottom wall, there were 13 pressure transducers at intervals of 40mm, denoted by "B1 B13" in Fig. 1. On the side wall, there were 8 pressure transducers, denoted by "S1 S8" in Fig. 1. Additionally, 12 K-type sheathed thermocouple denoted by "Tw1 Tw12" in Fig. 1 were located on the centerline of the bottom wall to monitor the heating process of isolator walls. Pressure profiles on isolator walls were measured at different isolator wall temperatures for different back pressures. 


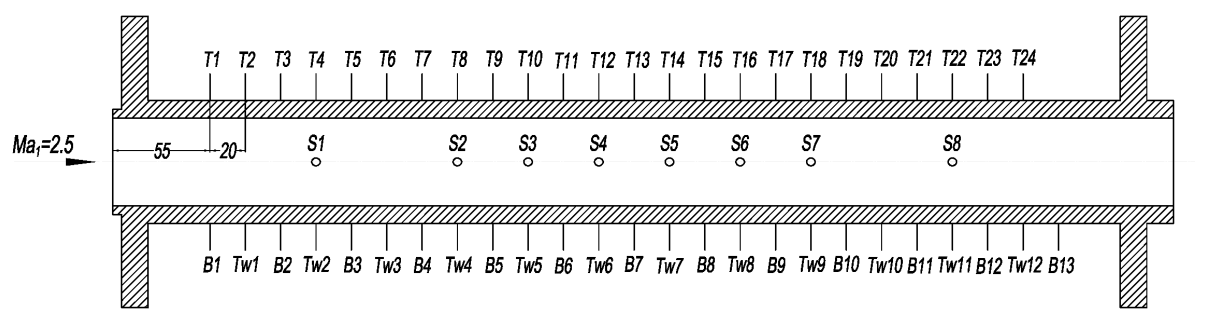

Fig. 1 Schematic of experimental isolator and measuring tap distributions

\section{B. Numerical description}

In addition to the measurements, numerical simulations were performed on a 2D domain including nozzle and isolator to provide tremendous information to understand the flow phenomenon. The current numerical algorithms are the same as those in our previous studies [27-29]. The full N-S equations for two-dimensional turbulent flow are solved by the finite volume method. The turbulence model of k- $\omega$ SST is employed to close the governing equations. The numerical flux through each cell face is evaluated using a second-order total variation diminishing (TVD) scheme based on an approximate Riemann solver named Harten-Lax-van Leer contact (HLLC). The minmod limiter is used to suppress spurious oscillations near the discontinuities while high-order accuracy is retained away from the jumps. A second-order fully implicit scheme is employed to discretize the time terms. In addition, methods of multi-grid and dual time-step are used to accelerate the convergence.

A comparison between numerical and experimental results was also made to guarantee the credibility of numerical results under the conditions of $\mathrm{T}_{\mathrm{t}}=1500 \mathrm{~K}, \mathrm{P}_{\mathrm{t}}=1.0 \mathrm{MPa}, \gamma=1.33$ and the wall temperature of isolator and nozzle being equal to 300K, as shown in Fig. 2. From Fig. 2b, it can be seen that numerical results are in agreement with the experiment data, in spite of some scatter being present. Additionally, the mass-weighted average Mach number at the nozzle exit from simulation is 2.5 , consistent with the design condition. Thus our results from CFD simulations can further assist in understanding effects of wall temperature on shock train. 


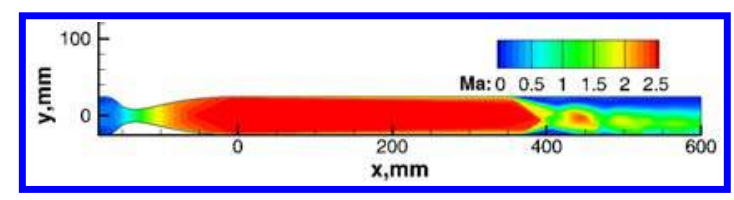

a) Mach contours

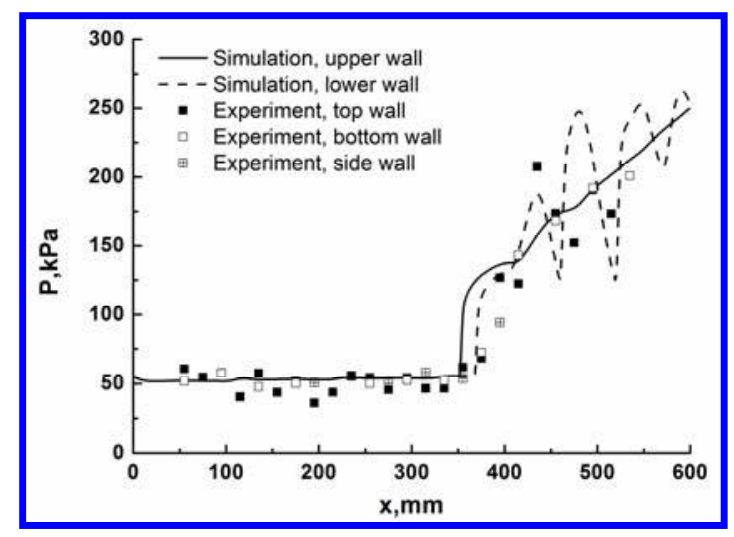

b) Wall pressure distributions

Fig. 2 Numerical verification at the condition of $T_{t}=1500 K, P_{t}=1.0 \mathrm{MPa}, \gamma=1.33$ and wall temperature of isolator and nozzle is equal to $300 \mathrm{~K}$.

\section{Results and discussion}

This section presents the effects of wall temperature and back pressure on shock train at two experimental flow conditions and one numerical flow condition. Condition I corresponds to the experimental condition of total temperature $\mathrm{T}_{\mathrm{t}}=1500 \mathrm{~K}$, total pressure $\mathrm{P}_{\mathrm{t}}=1.0 \mathrm{MPa}$, and Mach number $\mathrm{Ma}_{1}=2.5$ at the isolator entrance. Condition II corresponds to the experimental condition of total temperature $T_{t}=1000 \mathrm{~K}$, total pressure $\mathrm{P}_{\mathrm{t}}=0.84 \mathrm{MPa}$, and Mach number $\mathrm{Ma}_{1}=2.5$ at the isolator entrance. Condition III corresponds to the numerical condition of total temperature $\mathrm{T}_{\mathrm{t}}=1000 \mathrm{~K}$, total pressure $\mathrm{P}_{\mathrm{t}}=1.0 \mathrm{MPa}$, and Mach number $\mathrm{Ma}_{1}=2.5$ at the isolator entrance. In order to enrich flow information, numerical tests with a constant specific heat ratio of 1.33 at the condition I and III are also performed on a two-dimensional domain including a nozzle and isolator where the nozzle wall temperature is specified as $300 \mathrm{~K}$, identical to experimental tests. Although two dimensional numerical results cannot reflect three dimensional effects in a rectangular isolator, they assist to elucidate 
experimental phenomenon and qualitatively demonstrates the influencing trend of wall temperature on shock train and isolator performance.

\section{A. Shock train length}

A combination of experimental and numerical tests was conducted to study the variation trend of shock train length with wall temperature for different back pressures. The typical results are exhibited in Figs. $3 \sim 6$ and 8 , together with Table 1. Wall pressure rise is used to characterize shock train length. Figure 3 shows the experimental wall pressure distributions for different wall temperatures at the condition I and $\mathrm{P}_{\mathrm{B} 13} / \mathrm{P}_{\mathrm{T} 1} \approx 3.9$, where wall static pressure $\mathrm{P}$ is normalized by the pressure $\mathrm{P}_{\mathrm{T} 1}$ of the first measure point on the top wall and the exit back pressure generated by throttling is characterized by $\mathrm{P}_{\mathrm{B} 13} / \mathrm{P}_{\mathrm{T} 1}$. From Fig. 3a and $3 b$, it can be seen that little difference exists in wall pressure profiles and the starting position of pressure rise for $T_{w}=300 \mathrm{~K}, T_{w}=700 \mathrm{~K}$ and $\mathrm{T}_{\mathrm{w}}=900 \mathrm{~K}$, which is identical to the results of Fischer and Olivier [26] at a low back pressure level. This indicates wall temperature has little influence on shock train length at a low back pressure level.

With an increase of back pressure, shock train obviously turns long, and a notable difference is observed from the top and bottom wall pressure distributions for $\mathrm{T}_{\mathrm{w}}=300 \mathrm{~K}, \mathrm{~T}_{\mathrm{w}}=500 \mathrm{~K}$ and $\mathrm{T}_{\mathrm{w}}=700 \mathrm{~K}$ at the condition $\mathrm{I}$, as shown in Fig. 4, which corresponds to $\mathrm{P}_{\mathrm{B} 13} / \mathrm{P}_{\mathrm{T} 1} \approx 4.3$. As can be seen, with an increase of wall temperature, the starting position of shock train moves upstream, and wall pressure around the starting position of pressure rise also increases but that close to the exit is approximate to the same pressure level. This suggests that shock train length increases with an increase of wall temperature, leading to a reduction in the ability of isolator holding shock train. This conclusion is consistent with Chang et al' findings that wall cooling improves the maximum back pressure ratio of isolator [30].

With a further increase of back pressure, shock train moves close to the isolator entrance, and wall temperature effect is more visible, as shown in Fig. 5, which presents the experimental wall pressure 
distributions for $\mathrm{T}_{\mathrm{w}}=300 \mathrm{~K}, \mathrm{~T}_{\mathrm{w}}=500 \mathrm{~K}, \mathrm{~T}_{\mathrm{w}}=700 \mathrm{~K}$ and $\mathrm{T}_{\mathrm{w}}=900 \mathrm{~K}$ at the condition $\mathrm{I}$ and $\mathrm{P}_{\mathrm{B} 13} / \mathrm{P}_{\mathrm{T} 1} \approx 5.2$. It can be seen that the variation of shock train length with wall temperature is the same as Fig. 4, but an increase is identified in the increment of shock train length for the same two wall temperatures. This disparity for different back pressure can be more easily observed from experimental statistical results in Fig. 6. Figure 6 shows a series of experimental data distributions on variation of shock train length $\mathrm{s}$ with back pressure ratio $\mathrm{P}_{\mathrm{B} 13} / \mathrm{P}_{\mathrm{T} 1}$ between $\mathrm{T}_{\mathrm{w}}=300 \mathrm{~K}$ and $\mathrm{T}_{\mathrm{w}}=900 \mathrm{~K}$ at the condition $\mathrm{I}$. Here shock train length $\mathrm{s}$ for a specific back pressure ratio $\mathrm{P}_{\mathrm{B} 13} / \mathrm{P}_{\mathrm{T}}$ is defined as the streamwise distance between the last measure point B13 and the shock train starting position $\mathrm{x}_{\mathrm{st}}$ depicted in Fig. 7. $\mathrm{x}_{\mathrm{st}}$ is specified as the first measure point whose pressure being greater than or equal to $1.1 \mathrm{P}_{\mathrm{T} 1}$. Due to the existence of some scatter in Fig. 8, the trend line is plotted to specifically underline the effect of wall temperature on shock train length. For a constant shock train length, back pressure ratio $\mathrm{P}_{\mathrm{B} 13} / \mathrm{P}_{\mathrm{T} 1}$ reduces with an increase of wall temperature. The difference in $\mathrm{P}_{\mathrm{B} 13} / \mathrm{P}_{\mathrm{T} 1}$ between $\mathrm{T}_{\mathrm{w}}=300 \mathrm{~K}$ and $\mathrm{T}_{\mathrm{w}}=900 \mathrm{~K}$ increases with an increase of shock train length. These characteristics can be quantitatively observed from numerical results in Fig. 8 and Table 1. For example, the difference of shock train length between $T_{w}=300 \mathrm{~K}$ and $T_{w}=500 K, T_{w}=700 K$, $T_{\mathrm{w}}=900 \mathrm{~K}$ for $\mathrm{P}_{\mathrm{b}} / \mathrm{P}_{1}=4.8$ is in sequence 11-, 20-, 29-mm while for $\mathrm{P}_{\mathrm{b}} / \mathrm{P}_{1}=4.8$ is in sequence 13-, 24-, 33-mm. From the contents stated above, it can be found that the extent of wall temperature effect enhances with an increase of back pressure, indicating that wall temperature effect mainly appears in the interaction of waves with boundary layer. From Fig 8, it can be known that shock train mainly consists of a series of X type shocks, and the number of X type shock grows with back pressure. Naturally, wall temperature effect is strengthened by an increasing number of $\mathrm{X}$ type shock. At low back pressure, shock train just contains a few of $\mathrm{X}$ type shocks so that wall temperature effect is extremely weak and cannot be visible in wall pressure distributions due to the insufficient measure point. At high back pressure, shock train contains a series of $\mathrm{X}$ type shocks, and therefore wall temperature effect is bound to be more apparent. 


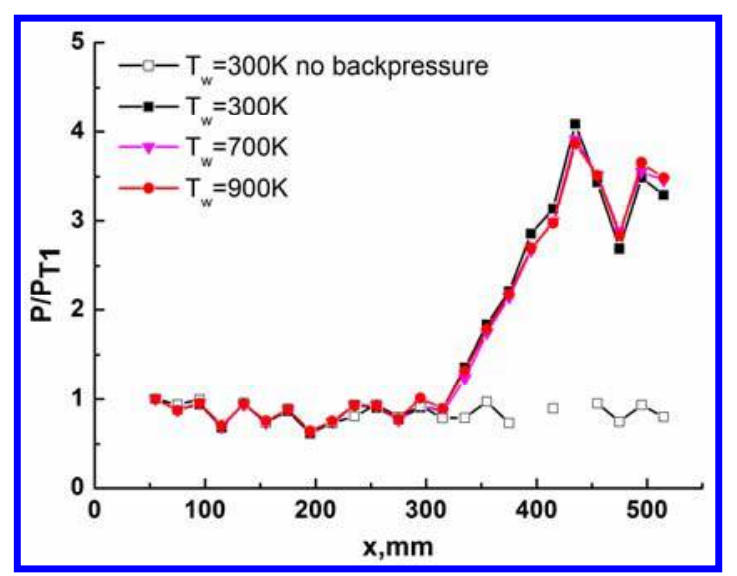

a) Top wall

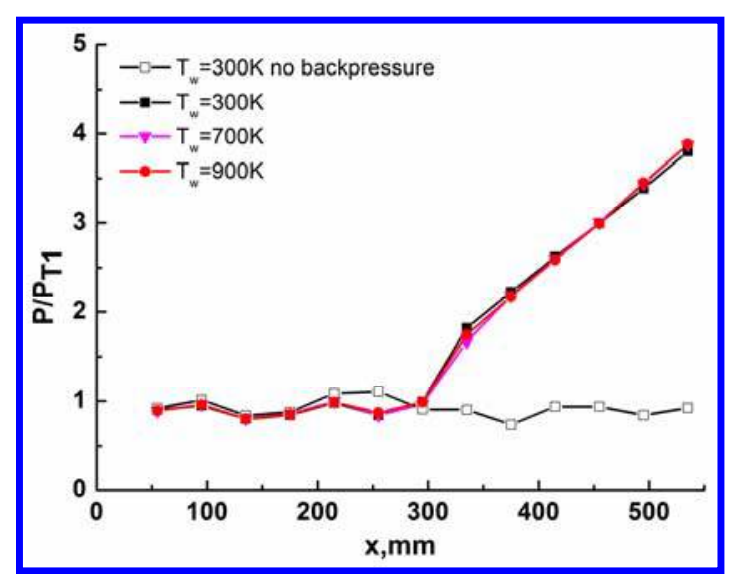

b) Bottom wall

Fig. 3 Wall pressure distributions of the rectangular isolator for different wall temperatures at the condition $I$ and $P_{\mathrm{B} 13 / P_{T 1}} \approx 3.9$ (experiment).

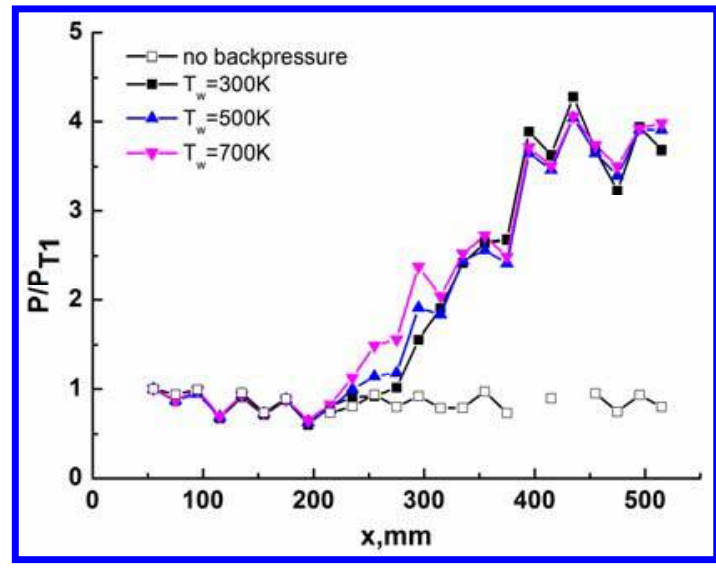

a) Top wall

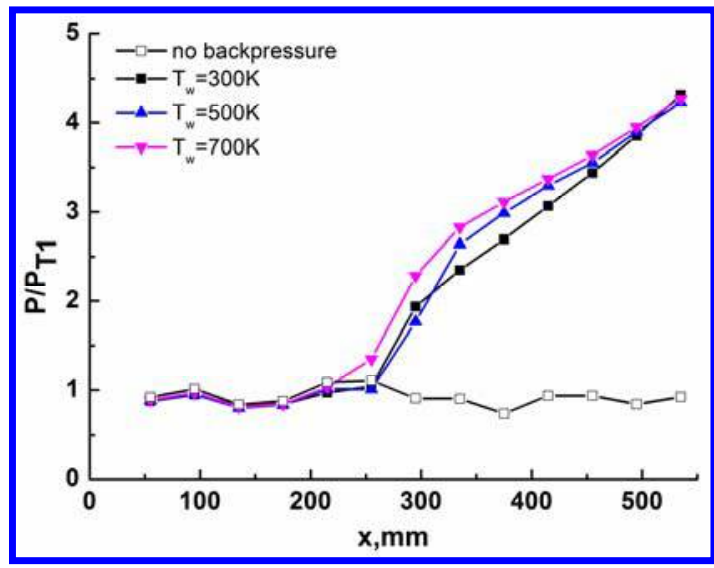

b) Bottom wall

Fig. 4 Wall pressure distributions of the rectangular isolator for different wall temperatures at the condition $I$ and $P_{\mathrm{B} 13} / P_{\mathrm{T} 1} \approx 4.3$ (experiment).

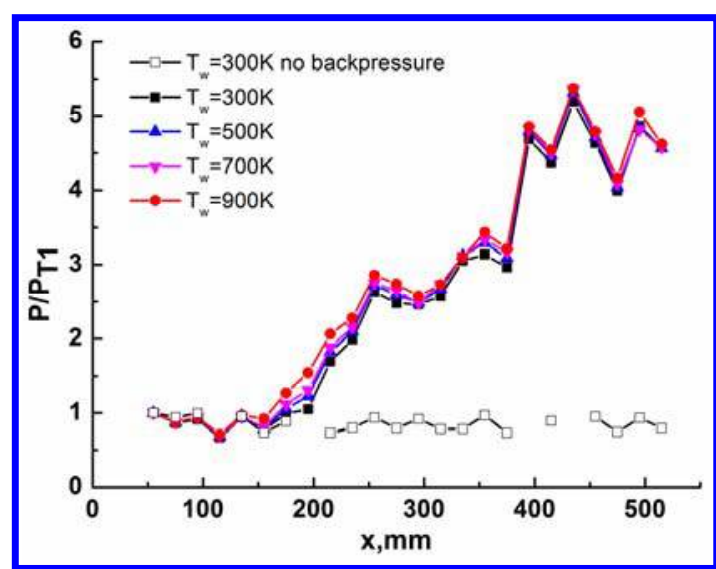

a) Top wall

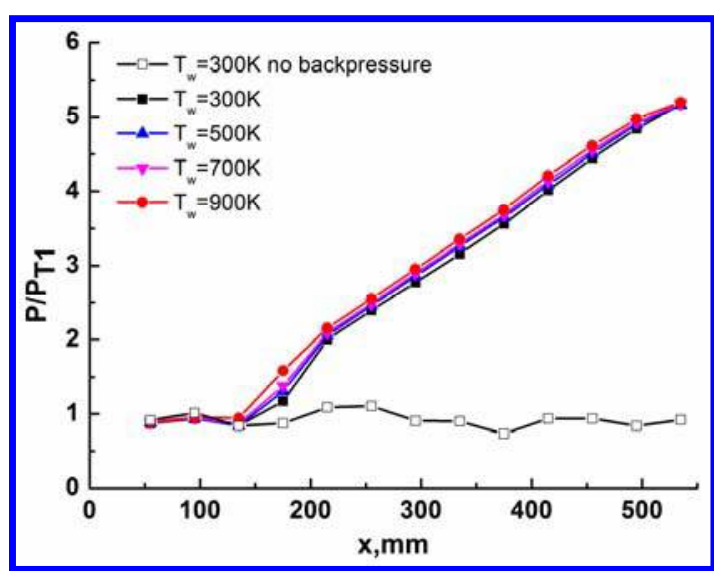

b) Bottom wall

Fig. 5 Wall pressure distributions of the rectangular isolator for different wall temperatures at the condition $I$ and $P_{B 13} / P_{T 1} \approx 5.2$ (experiment). 


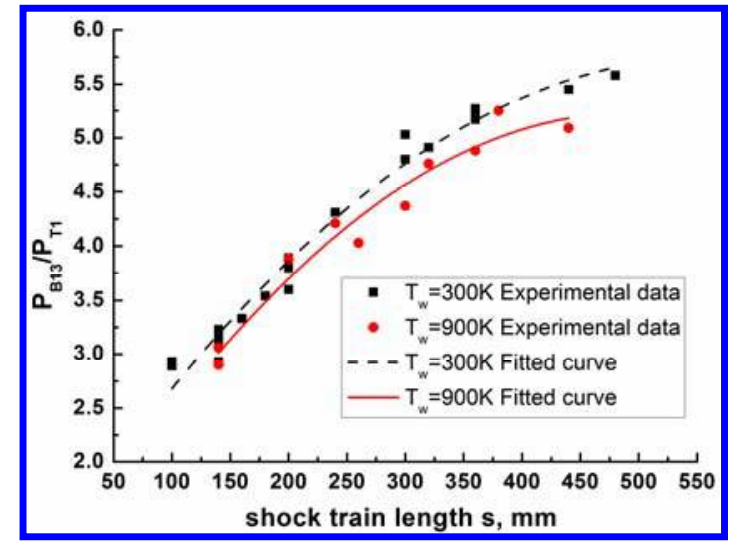

Fig. 6 Statistical analysis on variation of shock train length $s$ with back pressure ratio $\mathbf{P}_{\mathrm{B} 13} / \mathbf{P}_{\mathrm{T} 1}$ between $T_{w}=300 \mathrm{~K}$ and $T_{w}=900 \mathrm{~K}$ at the condition $I$ (experiment).

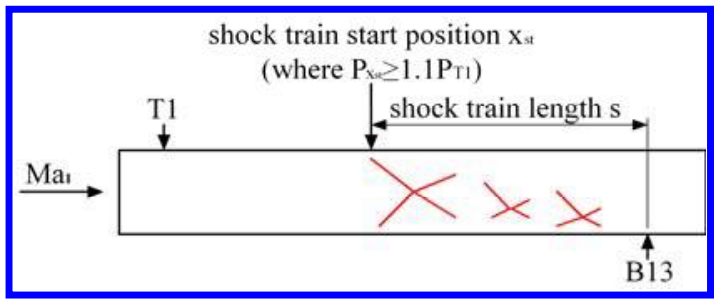

Fig. 7 Definition of shock train length s for a specific back pressure ratio $\mathbf{P}_{\mathrm{B} 13} / \mathbf{P}_{\mathrm{T} 1}$.

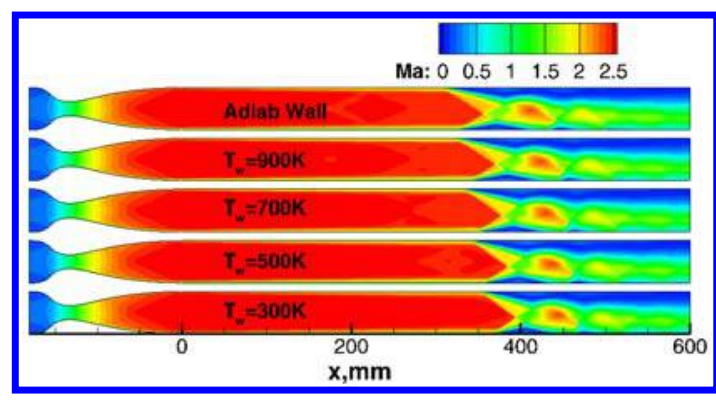

a) $\mathbf{P}_{b} / \mathbf{P}_{1}=4.8$

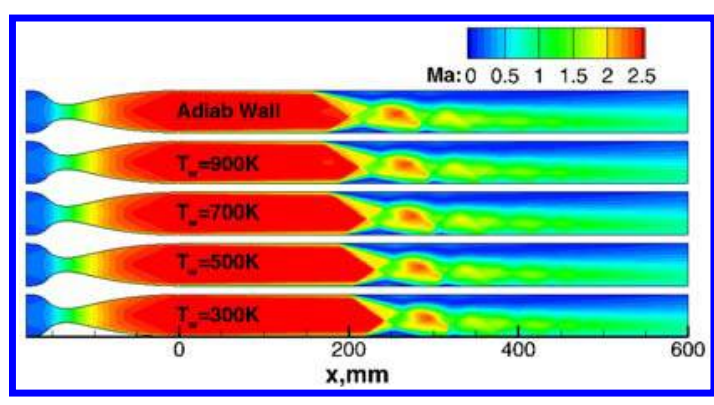

b) $\mathbf{P}_{\mathrm{b}} / \mathbf{P}_{\mathbf{1}}=\mathbf{6 . 2}$

Fig. 8 Mach contours for different wall temperatures from the 2D numerical simulation at the condition I and different back pressures.

\begin{tabular}{ccccccc}
\hline \hline \multicolumn{6}{c}{ Table 1 Shock train length distributions for different wall temperatures from } \\
CFD simulation at the condition I \\
\hline \multirow{2}{*}{ Wall condition } & $\mathrm{T}_{\mathrm{w}}(\mathrm{K})$ & 300 & 500 & 700 & 900 & Adiabatic wall \\
& $\mathrm{T}_{\mathrm{w}} / \mathrm{T}_{\mathrm{t}}$ & 0.2 & 0.33 & 0.47 & 0.6 & $\approx 1$ \\
\hline \multirow{2}{*}{$\mathrm{P}_{\mathrm{b}} / \mathrm{P}_{1}=4.8$} & $\mathrm{~s}(\mathrm{~mm})$ & 250 & 261 & 270 & 279 & 296 \\
& $\Delta \mathrm{s}(\mathrm{mm})$ & 0 & 11 & 20 & 29 & 46 \\
\hline \multirow{2}{*}{$\mathrm{P}_{\mathrm{b}} / \mathrm{P}_{1}=6.2$} & $\mathrm{~s}(\mathrm{~mm})$ & 403 & 416 & 427 & 436 & 450 \\
& $\Delta \mathrm{s}(\mathrm{mm})$ & 0 & 13 & 24 & 33 & 47 \\
\hline
\end{tabular}

With an increase of back pressure, the starting position of shock train moves upstream, and its corresponding boundary layer momentum thickness reduces with wall temperature. According to the correlation of Waltrup 
and Billig [5] expressed as Eq. (1), shock train length varies directly with $\theta^{0.25}$. For a constant Mach number and Reynolds number, shock train length from Eq. (1) should gradually decreases reduces with wall temperature. This predicted tendency is contrary to our results. Consequently, wall temperature effect cannot be elucidated by the boundary-layer momentum thickness $\theta$, the only parameter involved wall temperature effect in Eq. (1), and another dimensionless parameter has to be introduced to elucidate this influence. To figure out this parameter, a further numerical computation is performed at the condition III where $\mathrm{T}_{\mathrm{t}}=1000 \mathrm{~K}, \mathrm{P}_{\mathrm{t}}=1.0 \mathrm{MPa}$, and $\mathrm{Ma}_{1}=2.5$, as shown in Fig. 9 and Table 2. Compared to Fig. 9a and Table 1, shock train length obtained from the condition III is almost identical with that obtained from the condition I as long as the ratio of wall temperature to gas total temperature is approximately the same. For example, when $T_{w} / T_{t} \approx 0.3$, shock train length for $T_{w}=300 \mathrm{~K}$ and $\mathrm{T}_{\mathrm{t}}=1000 \mathrm{~K}$ is $256 \mathrm{~mm}$ at $\mathrm{P}_{\mathrm{b}} / \mathrm{P}_{1}=4.8$ while that for $\mathrm{T}_{\mathrm{w}}=500 \mathrm{~K}$ and $\mathrm{T}_{\mathrm{t}}=1500 \mathrm{~K}$ is $261 \mathrm{~mm}$. The tiny difference may be attributed to the disparity of Reynolds number for the two numerical conditions. To confirm numerical results, a series of experimental tests were conducted at the condition II where $\mathrm{T}_{\mathrm{t}}=1000 \mathrm{~K}, \mathrm{P}_{\mathrm{t}}=0.84 \mathrm{MPa}$, and Mach number $M a_{1}=2.5$. The typical experimental results are shown in Fig. 10. Figure 10 presents statistical results on variation of shock train length $\mathrm{s}$ with back pressure ratio $\mathrm{P}_{\mathrm{B} 13} / \mathrm{P}_{\mathrm{T} 1}$ for a constant ratio of wall temperature to total temperature $\left(\mathrm{T}_{\mathrm{w}} / \mathrm{T}_{\mathrm{t}}=0.6\right)$ with the two experimental conditions (Condition I and II). Some scatter exists in Fig. 10 due to the difference of Reynolds number, but it is experimentally demonstrated that shock train length is mainly dependent on the ratio of wall temperature to gas total temperature if the main factors except wall temperature and gas total temperature are approximately consistent. In addition, shock train length increases with the ratio of wall temperature to gas total temperature, as shown in Fig. 9 and Table 1 and 2, which coincides with the findings of Lin et al. [24, 25].

$$
\frac{s\left(M a_{1}^{2}-1\right) \operatorname{Re}_{\theta}^{1 / 4}}{D^{1 / 2} \theta^{1 / 2}}=50\left(\frac{P_{b}}{P_{1}}-1\right)+170\left(\frac{P_{b}}{P_{1}}-1\right)^{2}
$$




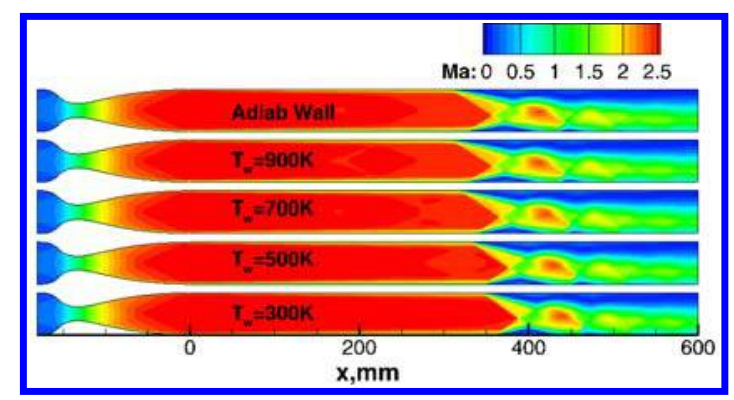

Fig. 9 Mach contour for different wall temperatures for $P R=4.8$ from the $2 D$ numerical simulation at the condition III.

Table 2 Shock train length distributions for different wall temperatures from CFD simulation at the condition III

\begin{tabular}{ccccccc}
\hline Wall condition & $\mathrm{T}_{\mathrm{w}}(\mathrm{K})$ & 300 & 500 & 700 & 900 & Adiabatic wall \\
Pressure ratio & $\mathrm{T}_{\mathrm{w}} / \mathrm{T}_{\mathrm{t}}$ & 0.3 & 0.5 & 0.7 & 0.9 & $\approx 1$ \\
\hline \multirow{2}{*}{$\mathrm{P}_{\mathrm{b}} / \mathrm{P}_{1}=4.8$} & $\mathrm{~s}(\mathrm{~mm})$ & 256 & 277 & 284 & 294 & 295 \\
& $\Delta \mathrm{s}(\mathrm{mm})$ & 0 & 21 & 28 & 38 & 39 \\
\hline
\end{tabular}

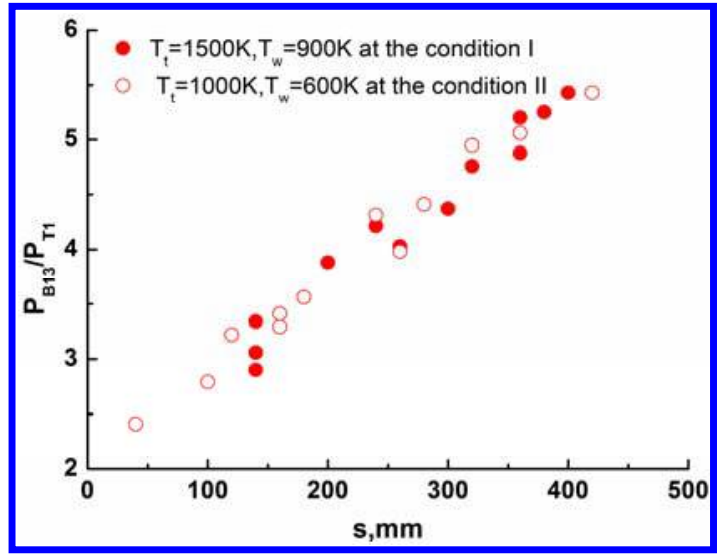

Fig. 10 Statistical analysis on variation of shock train length $s$ with back pressure ratio $P_{B 13} / P_{T 1}$ for a constant ratio of wall temperature to total temperature $\left(T_{w} / T_{t}=0.6\right)$ with the two wall and total temperatures being different from each other (experiment).

\section{B. Physical Mechanism}

The inner physical mechanism of an increase in wall temperature degrading isolator performance and increasing shock train length can be explained in below. Figure 11 shows typical static temperature profiles in the boundary layer for different wall temperatures. It can be noted that static temperature level in the boundary layer increases remarkably with wall temperature. Because static pressure keeps constant for different wall temperatures, the density increases considerably with wall temperature from the state $\mathrm{P}=\rho \mathrm{RT}$. Thus the effect of wall cooling is to reduce the boundary layer thickness $\delta$, as reported in the literature [28]. The fullness of 
velocity distributions in the boundary layer can be denoted by $\mathrm{u}_{\infty} / \delta$. Consequently, with an increase of wall temperature, both velocity $u$ and density $\rho$ reduces, leading to a reduction of kinetic energy $\rho u^{2}$ in the boundary layer. Correspondingly, the incipient pressure separating the boundary layer drops. This will lead to a more easily formation of shock train in the isolator with high wall temperature. Consequently, shock train length increases with an increase of wall temperature for a constant back pressure level.

From the definition of boundary layer momentum thickness Eq. (2), a striking feature is identified that boundary layer momentum thickness $\theta$ will decrease with wall temperature. Shock train length s predicted by the correlation Eq. (1) of Waltrup and Billig [5] will reduce. The predicting tendency conflicts with our results and majority of previous conclusions [15, 21-25]. An improved correlation is urgently needed to accounting for wall temperature effects.

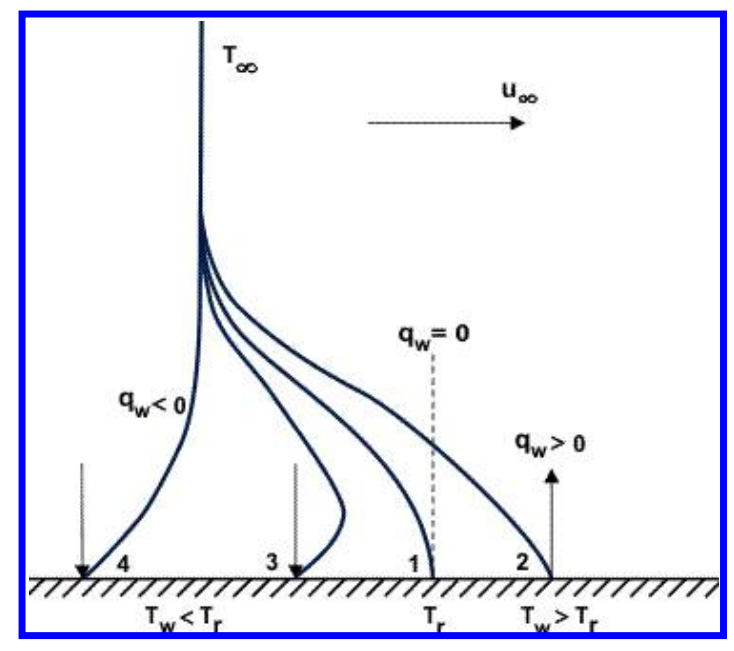

Fig. 11 Typical static temperature profiles in the boundary layer for different wall temperatures

$$
\theta=\int_{0}^{\infty} \frac{\rho u}{\rho_{\infty} u_{\infty}}\left(1-\frac{u}{u_{\infty}}\right) d y
$$

\section{Correlation of shock train length and wall temperature effects}

Although Eq. (1) is derived from the cold airflow experiments with a cylindrical isolator, it still works in principle for rectangular cross sections if the parameter $\mathrm{D}$ is replaced by the duct height $\mathrm{H}$ [11]. As noted in Sec. 
III.B, it is concluded that the ratio of wall temperature to gas total temperature can be introduced to characterize wall temperature effect on shock train. Thus we propose the following relationship denoted by Eq. (3) to cover the relevant parameters.

$$
f\left(\frac{T_{w}}{T_{t}}\right) \frac{s\left(M a_{1}^{2}-1\right) \operatorname{Re}_{\theta_{1}}^{1 / 4}}{H^{1 / 2} \theta_{1}^{1 / 2}}=50\left(\frac{P_{b}}{P_{1}}-1\right)+170\left(\frac{P_{b}}{P_{1}}-1\right)^{2}
$$

From the reference [1], it is known that the specific heat ratio $\gamma$ of air will reduces with an increase of static temperature when static temperature is larger than $400 \mathrm{~K}$, and otherwise $\gamma=1.4$. Data to correlate Eq. (1) are obtained from the airflow experiments where $\gamma=1.4$, but our data are obtained from the high enthalpy flow tests where $\gamma \approx 1.33$. Thus the specific heat ratio effect also need be considered. From the oblique shock relationship denoted by Eq. (4), we known that pressure ratio $\mathrm{P}_{2} / \mathrm{P}_{1}$ across an oblique shock with shock angle of $\beta$ will reduce with a reduction of $\gamma$ for a constant approach Mach number, contributing to a longer shock train. In view of shock train consisting of a series of $X$ type shocks, the form of $\gamma$ in Eq. (4) is adopted in Eq. (5) to characterize specific heat ratio effect on shock train. To coincide with Eq. (1) for $\gamma=1.4$ at the absence of wall temperature effect, let $\left(\frac{\varphi_{0} \gamma}{\gamma+1} M a_{1}^{2}-\frac{\gamma-1}{\gamma+1}\right)_{\gamma=1.4}=M a_{1}^{2}-1$, we obtain $\varphi_{0}=1.7-\frac{1.4}{M a_{1}^{2}}$. Thus Equation (5) is expressed as Eq. (6). It can be noted that shock train length given by Eq. (6) increases with a reduction of $\gamma$ for a fixed back pressure, consistent with physical mechanism.

$$
\begin{gathered}
\frac{P_{2}}{P_{1}}=\frac{2 \gamma}{\gamma+1}\left(M a_{1} \sin \beta\right)^{2}-\frac{\gamma-1}{\gamma+1} \\
f\left(\frac{T_{w}}{T_{t}}\right) \frac{S\left(\frac{\varphi_{0} \gamma}{\gamma+1} M a_{1}^{2}-\frac{\gamma-1}{\gamma+1}\right) \operatorname{Re}_{\theta_{1}}^{1 / 4}}{H^{1 / 2} \theta_{1}^{1 / 2}}=50\left(\frac{P_{b}}{P_{1}}-1\right)+170\left(\frac{P_{b}}{P_{1}}-1\right)^{2} \\
f\left(\frac{T_{w}}{T_{t}}\right) \frac{S\left(\frac{1.7 \gamma}{\gamma+1} M a_{1}^{2}-\frac{2.4 \gamma-1}{\gamma+1}\right) \operatorname{Re}_{\theta_{1}}^{1 / 4}}{H^{1 / 2} \theta_{1}^{1 / 2}}=50\left(\frac{P_{b}}{P_{1}}-1\right)+170\left(\frac{P_{b}}{P_{1}}-1\right)^{2}
\end{gathered}
$$




$$
\begin{gathered}
M a=\int_{-0.5 H}^{0.5 H} \rho u \phi d y / \int_{-0.5 H}^{0.5 H} \rho u d y \\
\theta=\int_{-0.5 H}^{0} \frac{\rho u}{\rho_{y=0} u_{y=0}}\left(1-\frac{u}{u_{y=0}}\right) d y \quad \text { or } \quad \int_{0.5 H}^{0} \frac{\rho u}{\rho_{y=0} u_{y=0}}\left(1-\frac{u}{u_{y=0}}\right) d y
\end{gathered}
$$

According to Eq. (6), the function $\mathrm{f}\left(\mathrm{T}_{\mathrm{w}} / \mathrm{T}_{\mathrm{t}}\right)$ can be calculated using the known parameters of $\mathrm{s}, \mathrm{Ma}_{1}, \gamma, \theta_{1}$, $\operatorname{Re}_{\theta_{1}}, \mathrm{P}_{\mathrm{b}} / \mathrm{P}_{1}$ and $\mathrm{H}$, where the subscript 1 denotes the starting location of shock train. Due to the parameters $\mathrm{Ma}_{1}$, $\theta_{1}$ without measured in the experiments, the function $f\left(T_{w} / T_{t}\right)$ are only obtained from numerical data. The mass-average Mach number is calculated by Eq. (7), and the boundary layer momentum thickness is computed by Eq. (8). The flow-channel geometry height $\mathrm{H}$ is $50 \mathrm{~mm}$. Figure 15 shows the variation of the function $\mathrm{f}\left(\mathrm{T}_{\mathrm{w}} / \mathrm{T}_{\mathrm{t}}\right)$ with the ratio $T_{w} / T_{t}$ based on the present data. It can be observed that the function $f\left(T_{w} / T_{t}\right)$ reduces nonlinearly with an increase of the ratio $T_{w} / T_{t}$. When the ratio $T_{w} / T_{t}$ increases from a small value, the $f\left(T_{w} / T_{t}\right)$ drops rapidly. When $T_{w} / T_{t} \rightarrow 1$, the slope of the function $f\left(T_{w} / T_{t}\right)$ with the ratio $T_{w} / T_{t}$ turns small. Thus a power function expressed by Eq. (9) is introduced to characterize this tendency. To make the correlation be as simple as possible, $\varphi_{1}$ and $\varphi_{2}$ in Eq. (9) are viewed as the unknown constant coefficients, leading to $\varphi_{1}=1.91$ and $\varphi_{2}=-0.18$. Some scatter is noted in Fig. 12 due to the lack of accounting for the mutual interaction between wall temperature effects and back pressure levels. Substitute the Eq. (9) into Eq. (6), a modified correlation Eq. (10) is finally settled. Figure 13 shows the degree of success obtained in the correlation Eq. (10). Some scatter is present but Equation (10) adequately represents all of the data. Compared with the correlation Eq. (1) of Waltrup and Billig [5], the modified correlation covers more physical influencing factors, not only considered the wall temperature effect, but counted for the specific heat ratio influence, and can well explain the main factor effects on shock train length. Need of special note is that the data to correlate Eq. (10) is just from $2 \mathrm{D}$ numerical simulation at the condition of $\mathrm{Ma}_{1}=2.5$. The prediction accuracy of Eq. (10), especially at other flow conditions and geometries, needs to be verified by the further experimental data. 


$$
\begin{gathered}
f\left(\frac{T_{w}}{T_{t}}\right)=\varphi_{1}\left(\frac{T_{w}}{T_{t}}\right)^{\varphi_{2}} \\
\frac{1.91 s\left(\frac{1.7 \gamma}{\gamma+1} M a_{1}^{2}-\frac{2.4 \gamma-1}{\gamma+1}\right) \operatorname{Re}_{\theta_{1}}^{1 / 4}}{H^{1 / 2} \theta_{1}^{1 / 2}\left(\frac{T_{w}}{T_{t}}\right)^{0.18}}=50\left(\frac{P_{b}}{P_{1}}-1\right)+170\left(\frac{P_{b}}{P_{1}}-1\right)^{2}
\end{gathered}
$$

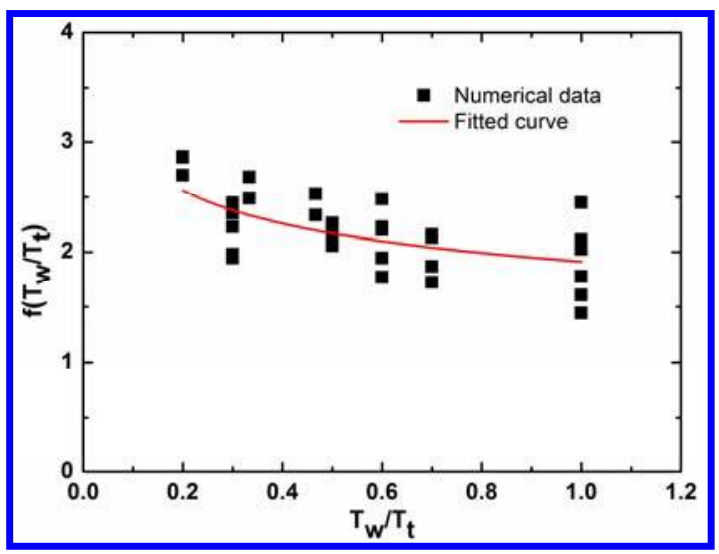

Fig. 12 Variation of the function $f\left(T_{w} / T_{t}\right)$ with the ratio $T_{w} / T_{t}$ based on numerical data.

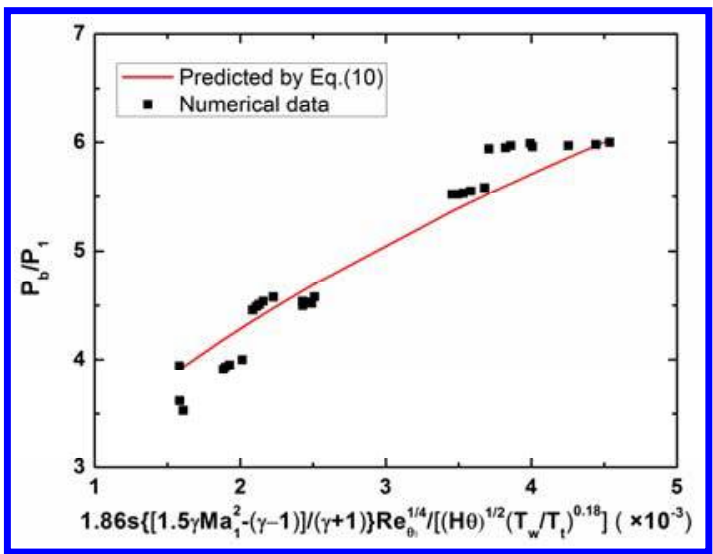

Fig. 13 A comparison of our numerical data against those from Eq. (10).

\section{Conclusions}

Experiments were carried out to study effects of temperature on shock train structures and isolator performance in a direct-connect test facility using high-temperature vitiated air. A 2D supersonic nozzle with Mach number of 2.5 was used to provide the supersonic flow entering the isolator with a $50 \mathrm{~mm} \times 70 \mathrm{~mm}$ rectangular configuration. Wall static pressures and surface temperatures along isolator walls were measured to characterize shock train lengths and pressure profiles at two typical experimental conditions. In addition to the 
measurements, numerical simulations were performed on a 2D domain including nozzle and isolator to provide more tremendous information. Numerical quantitative data were also employed to correlate wall temperature effects. The major conclusions were as follows:

(1) Wall temperature plays an important role in the length of shock train. With an increase of wall temperature, shock train length increases and isolator performance degrades, consistent with majority of previous conclusions [15, 21-25] but contrary to the tendency given by the correlation of Waltrup and Billig [5]. An improved correlation is urgently needed to accounting for wall temperature effects. In addition, the extent of wall temperature effect enhances with an increase of back pressure level.

(2) Wall temperature effect can be can be characterized by the ratio of wall temperature to gas total temperature. Shock train length increases with ratio of wall temperature togas total temperature. In view of the difference in specific heat ratio between high-temperature vitiated air and cold airflow, both the ratio of wall temperature to total temperature and specific heat ratio are introduced to improve the correlation of Waltrup and Billig [5] for predicting shock train length of practical design. The modified correlation covers more physical influencing factors, and can well explain the variation trend of shock train length with the main factors.

(3) Need of special note is that the modified correlation based on our numerical data needs to be verified by the further experimental data, especially at other flow conditions and geometries. The physical phenomena of the observed wall temperature effect are also present at other flow conditions and geometries, and so similar behavior of the flowfield is expected there as well.

\section{References}

[1] Heiser W H, Pratt D T. Hypersonic Airbreathing Propulsion [M]. Washington D C: AIAA, 1993.

[2] Curran E T, Murthy S N B. Scramjet Propulsion [M]. Washington, D C:AIAA, 2001.

-[3] Billig F S, Dugger G L, Waltrup P J. Inlet combustor interface problems in scramjet engines. The First International Symposium on Air Breathing Propulsion, Marseille, France, June 1972. 
[4] Mtsuo K, Miyazato Y, Kim H D. "Shock train and pseudo-shock phenomena in internal gas flows," Progress in Aerospace Sciences, Vol. 35, 1999, pp. 33-100.

[5] Waltrup P J, Billig F S. "Structure of Shock Waves in Cylindrical Ducts. AIAA Journal,” Vol. 11, No. 10, 1973, pp. $1404-1408$.

[6] Carroll B F, Dutton J C. "Characteristics of Multiple Shock-Wave/Turbulent Boundary-Layer Interactions in Rectangular Ducts,” Jet of Propulsion, Vol. 6, No. 2, 1990, pp. 186-193.

[7] Carroll B E, Dutton J C. "Turbulence phenomena in a multiple normal shock Wave/turbulent boundary layer interaction," AIAA Journal, Vol. 30, No. 1, 1992, pp. 43-48.

[8] Matsuo K. "Shock train and pseudo-shock phenomena in supersonic internal flows". Journal of Thermal Science, 2003, Volume 12, No. 3, pp. 204-208.

[9] Weiss A., Grzona A., Olivier H. "Behavior of shock trains in a diverging duct," Exp. Fluids, Vol.49, No. 2, 2010, pp.355-365.

[10] Tang H. J., Sun S, Huang H X. "Behavior of shock trains in a hypersonic inlet/isolator model with complex background waves,” Exp. Fluids, Vol. 53, No. 6, 2012, pp. 1647-1661.

[11] Bement D A, Stevens J R, Thompson M W. "Measured operating characteristics of a rectangular combustor/inlet isolator," AIAA Paper 90-2221, 1990.

[12] Lin P. “Geometric effects on pre-combustion shock train in constant area isolators," AIAA paper 93-1838, 1993.

[13] Cox-Stouffer S K, Hagenmaier M A. “The Effect of Aspect Ratio on Isolator Performance,” AIAA paper 2001-0519, 2001.

- [14] Baker P J. "Heat Transfer in a Supersonic Parallel Diffuser," Journal of Mechanical Engineering Science, Vol. 7, No. 1, 1965, pp.1-7.

- [15] Cuffel R F, Backf L H. "Flow and Heat Transfer Measurements in a Pseudo-Shock Region with Surface Cooling," AIAA Journal, Vol. 14, NO, 12, 1976, pp. 1716-1722.

[16] Coet M C, Chanetz B. "Thermal effects in shock wave/boundary layer interactions in hypersonic processes," Recherche Aerospatiale/Aerospace Research, Vol. 4, 1994, pp.251-268.

[17] Bleilebens M, Olivier H. "On the influence of elevated surface temperatures on hypersonic shock wave/boundary layer interaction at a heated ramp model," Shock Waves, Vol. 15, 2006, pp. 301-312.

[18] Olivier H, Habermann M. “Use of shock tunnels for hypersonic propulsion testing,” AIAA Paper 1999-2447, 1999.

[19] Reinartz B U. “Computation of wall heat fluxes in hypersonic inlet flows,” AIAA Paper 2002-0506, 2002.

-[20] John B, Kulkarni V N, Natarajan G. "Shock wave boundary layer interactions in hypersonic flows," International Journal of Heat and Mass Transfer, Vol. 70, 2014, pp. 81-90.

[21] Fischer C, Olivier H. "Experimental Investigation of the Internal Flow Field of a Scramjet Engine," AIAA paper 2009-7369, 2009.

[22] Fischer C, Neuenhahn T, Olivier H. "Numerical Investigation of the Isolator Flow Field of a SCRAMJET Engine with Elevated Wall Temperatures," New Results in Numerical and Experimental Fluid Mechanics VII, Notes on Numerical Fluid Mechanics and Multidisciplinary Design (NNFM),Vol. 112, 2010, pp. 415-422.

[23] Fischer C, Olivier H. "Experimental Investigation of the Shock Train in an Isolator of a Scramjet Inlet," AIAA paper 2011-2220, 2011.

[24] Lin K C, Tam C J, Jackson K R, et al. "Characterization of Shock Train Structures Inside Constant-Area Isolators of Model Scramjet Combustors," AIAA paper 2006-0816, 2006.

[25] Lin K C, Tam C J, Eklund D R, et al. "Effects of Temperature and Head Transfer on Shock Train Structures Inside Constant-Area Isolators," AIAA paper 2006-0817, 2006.

[26] Fischer C and Olivier H. "Experimental Investigation of Wall and Total Temperature Influence on a Shock Train," AIAA Journal, Vol. 54, No. 4, 2014, pp. 757-766. 
[27] Lu, H. B., Yue, L. J., Xiao, Y. B., and Zhang, X. Y., "Interaction of isentropic compression waves with a bow shock.," AIAA Journal, Vol.51, NO. 10, 2013, pp. 2474-2484.

-[28] Lu, H. B., Yue, L. J., and Chang, X. Y., "Flow characteristics of hypersonic inlets with different cowl-lip blunting methods," Sci. China-Phys. Mech. Astron.,Vol. 57, No. 4, 2014, pp. 741-752.

[29] Yue L. J., Lu H. B., Xu X. and Chang X. Y., "Aerothermal characteristics of bleed slot in hypersonic flows.," Sci. China-Phys. Mech. Astron.,Vol. 58 No. 10, 2015, pp. 104703.1-14.

[30] Chang J, Bao W, Yu D, et al. "Effects of wall cooling on performance parameters of hypersonic inlets," Acta Astronuatica, Vol. 65, 2009, pp. 467-476.

[31] Anderson J D. Hypersonic and high temperature gas dynamics, $2^{\text {nd }}$ ed. Reston V A: AIAA, 2006. 